\title{
Antioxidant and anti-diabetic effects of caffeic acid in a rat model of diabetes
}

\author{
Wenguang Xu${ }^{1}$, Qiong Luo ${ }^{2 *}$, Xiuying Wen ${ }^{3}$, Ming Xiao ${ }^{1}$, Qijian Mei ${ }^{1}$ \\ ${ }^{1}$ Department of Geriatrics, ${ }^{2}$ Department of Endocrinology, General Hospital of Yangtze River Shipping; ${ }^{3}$ Department of \\ Traditional Chinese Medicine, Liyuan Hospital, Tongji Medical College, Huazhong University of Science and Technology, \\ Wuhan, Hubei, China
}

*For correspondence: Email: 11257502@qq.com

Sent for review: 17 February 2020

Revised accepted: 24 May 2020

\begin{abstract}
Purpose: To determine the antioxidant and anti-diabetic potential of a natural flavonoid, caffeic acid in a streptozotocin-induced diabetic rat model.

Methods: Experimental diabetes was induced in Wistar rats using streptozotocin injection. Caffeic acid was administered orally on daily basis for 5 weeks. A glucometer was used to monitor fasting blood glucose levels. Insulin levels were estimated using enzyme-linked immunosorbent assay (ELISA). The antioxidant potential of caffeic acid was measured by determining the activities of superoxide dismutase $(S O D)$ and catalase (CAT), and levels of reduced glutathione (GSH) in rat liver. Standard assays were performed to determine the lipid profile of the rats. Histopathological analysis was performed to determine differences in microscopic structures of pancreas among the different treatment groups.

Results: Caffeic acid administration resulted in significant enhancement of serum insulin level, and decrease in blood glucose level of diabetic rat models $(p<0.05)$. Caffeic acid exerted antioxidant effects by significantly increasing GSH levels and activities of CAT and SOD ( $p<0.05)$. Histological examination of the pancreas depicted normal islet morphology under caffeic acid administration in diabetic rats.

Conclusion: These results reveal the antioxidant potential and anti-diabetic effect of caffeic acid in a diabetic rat model and point towards the potential applicability of caffeic acid in the management of diabetes mellitus.
\end{abstract}

Keywords: Diabetes mellitus, Streptozotocin, Caffeic acid, Phenolics, Anti-diabetic, Antioxidant

\begin{abstract}
This is an Open Access article that uses a fund-ing model which does not charge readers or their institutions for access and distributed under the terms of the Creative Commons Attribution License (http://creativecommons.org/licenses/by/4.0) and the Budapest Open Access Initiative (http://www.budapestopenaccessinitiative.org/read), which permit unrestricted use, distribution, and reproduction in any medium, provided the original work is properly credited.
\end{abstract}

Tropical Journal of Pharmaceutical Research is indexed by Science Citation Index (SciSearch), Scopus, International Pharmaceutical Abstract, Chemical Abstracts, Embase, Index Copernicus, EBSCO, African Index Medicus, JournalSeek, Journal Citation Reports/Science Edition, Directory of Open Access Journals (DOAJ), African Journal Online, Bioline International, Open-J-Gate and Pharmacy Abstracts

\section{INTRODUCTION}

Currently, diabetes is one of prevalent human diseases across the globe [1]. Excessive intake of carbohydrate and fat-rich diets has been shown to be responsible for the development of metabolic disturbances leading to the induction of diabetes mellitus in humans [2]. Diabetes mellitus accounts for a significant level of mortality, mainly in developed countries [3]. The disease develops as a result of abnormal insulin production or impairment of its action, resulting in marked increases in fasting blood glucose levels [4]. 
Rodent-based diabetic models have been used for the evaluation of different anti-diabetic drugs, and to unveil the molecular events associated with the disease. Diabetes has been induced in rat models using a number of chemical compounds. Streptozotocin is the most commonly used drug for induction of diabetes in rats [4]. It works by destroying the pancreatic $\beta$ cells, thereby inhibiting insulin secretion which leads to diabetic state [5]. The currently employed therapeutic agents against diabetes mellitus aim at maintaining normal blood glucose levels. However, owing to the heterogeneous nature of these therapeutic strategies, the successes achieved have been very limited [6].

Against this backdrop, studies are currently directed at achieving better clinical results. Phenolic compounds are one of the dominant classes of natural compounds with promising potential in combating human diseases [7]. These compounds show antioxidant, antiinflammatory and anticancer effects, and as such have been used in traditional medicines from time immemorial [8]. Previous studies have shown that phenolic compounds exerted antidiabetic effects in rat models [9].

The present study was designed to evaluate the anti-diabetic effect of caffeic acid (Figure 1) in a rat model of diabetes mellitus.

\section{EXPERIMENTAL}

\section{Animals}

Healthy male adult male Wistar rats were used in this study. The average body weight of the animals was $165 \pm 10 \mathrm{~g}$. The rats were maintained in well-ventilated rooms at a temperature of $25 \pm 3^{\circ} \mathrm{C}$ and approximately $12 \mathrm{~h}$ light/12-h dark photo period. Standard pelletbased diet and free access to water were provided to the rats. The study was approved the Research ethics committee of Huazhong University of Science and Technology (approval no. HUS/6762/2019). All the standard international guidelines were followed during the study as described previously [10].

\section{Induction of diabetes}

The rats were fasted for about $14 \mathrm{~h}$ prior to intraperitoneal injection of streptozotocin $(1 \mathrm{~mL} / \mathrm{rat})$. After three days of injection, induction of diabetes was confirmed by estimating fasting blood glucose levels. Rats with fasting glucose levels $\geq 240 \mathrm{mg} / \mathrm{dL}$ were taken as diabetic and were used in the study. The animals were divided into four experimental groups, with 8 rats per group. The rat groups were: group I (control, non-diabetic rats), group II (diabetic rats), group III (diabetic rats administered caffeic acid at a dose of $25 \mathrm{mg} / \mathrm{kg}$ ), and group IV (diabetic rats administered caffeic acid at a dose of $35 \mathrm{mg} / \mathrm{kg}$ ) daily for 5 weeks. At the end of the $5^{\text {th }}$ week, the rats were anaesthetized and subsequently sacrificed. Blood samples were collected and subjected to high speed centrifugation for $15 \mathrm{~min}$ to obtain serum samples which were used for biochemical analyses.

\section{Evaluation of blood glucose and plasma insulin levels}

A glucometer (Accu-Chek, Mannheim, Germany) was used for determination of fasting glucose levels of rat blood at the end of each week, while ELISA kits $(\mathrm{GmbH})$ were used for determining plasma insulin levels.

\section{Determination of antioxidant parameters}

Activities of SOD and CAT, and levels of GSH were determined using the following standard protocols: A reaction mixture consisting of phosphate buffer (25 mM, pH 7.8); EDTA (0.25 $\mathrm{mM})$, quercetin $(0.05 \mu \mathrm{M})$ and TEMED $(0.8 \mathrm{mM})$ was used to assay SOD activity by estimating the inhibition of quercetin oxidation at $406 \mathrm{~nm}$. One unit of SOD activity was taken as amount of enzyme that produced $50 \%$ inhibition of oxidation. Reduction of $\mathrm{H}_{2} \mathrm{O}_{2}$ was used to measure CAT activity at $240 \mathrm{~nm}$, with a reaction mixture containing phosphate buffer $(50 \mathrm{mM}, \mathrm{pH}$ 7.0); EDTA (0.5 mM), $\mathrm{H}_{2} \mathrm{O}_{2} \quad(10 \mathrm{mM})$ and TritonX100 $(0.012 \%)$. The activity of CAT activity was expressed as $\mu \mathrm{mol} \mathrm{H}_{2} \mathrm{O}_{2}$ decayed/min $/ \mathrm{mg}$ protein. In the determination of GSH levels, the samples were added to a 96-well plate. The final volume was made up to $100 \mu \mathrm{Lusing}$ phosphate buffer (100 mM, pH 8.0); EDTA (5 mM) and Ophthalaldehyde $(25 \mu \mathrm{L})$. The plate was then subjected to incubation at $37^{\circ} \mathrm{C}$ for $45 \mathrm{~min}$, after which GSH levels were determined by recording the fluorescent emission at $425 \mathrm{~nm}$ after the sample excitation at $340 \mathrm{~nm}$.

\section{Measurement of serum lipid profile}

The levels of serum triglycerides (TGIs), total cholesterol (TChl) level and high-density lipoprotein cholesterol (HDL-C) were determined using Randox assay kits (Randox Laboratories Ltd., United Kingdom). Friedewald's formula was used to calculate the concentartion of low-density lipoprotein (LDL-C) cholesterol as in Eq 1.

LDL-C $=[($ TChl-HDL-C)-TGIs $] / 5$ 


\section{Histopathological examination of pancreatic tissue}

Three rats were randomly taken from each animal group and were sacrificed under anaesthesia. The pancreas was removed from the sacrificed animals and fixed using $10 \%$ formalin (neutral-buffered). The tissues were fixed by dehydration with alcohol, followed by paraffin embedding. Thereafter, 4.5- $\mu \mathrm{m}$ sections were sliced from the rat pancreatic tissues and stained with haematoxylin and eosin (H\&E). The sections were mounted using disterenephthalate xylene, and histological examination was done by a trained pathologist who was blind to the treatments used. The islet cell injuries were analysed through microscopic examination of at least a dozen fields from each pancreatic section.

\section{Statistical analysis}

The experiments were performed in three replicates, and the data are presented as mean \pm standard deviation (SD). The $p$-values were calculated using Student's t-test. Statistical analysis was performed using GraphPad Prism 7.0 offline software. Values of $p<0.05$ were taken as indicative of statistical significance.

\section{RESULTS}

Caffeic acid restored blood glucose and insulin levels in diabetic rats

The diabetic rats showed significantly higher levels of blood glucose, low plasma insulin and low body weight, relative to the normal control group (Table 1). However, daily oral administration of caffeic acid at doses of 25 $\mathrm{mg} / \mathrm{kg}$ body weight (group III) and $35 \mathrm{mg} / \mathrm{kg}$ body weight (group IV) led to significant reductions in the blood glucose levels, when compared to the diabetic group (group II; Figure 2). Caffeic acid treatment also significantly enhanced plasma insulin levels (Figure 3).

\section{Caffeic acid exerted antioxidant effects in diabetic rats}

The streptozotocin-induced diabetic rats (group II) exhibited significantly reduced liver activities of SOD (Figure $4 \mathrm{~A}$ ) and CAT (Figure $4 \mathrm{~B}$ ), and reduced $\mathrm{GSH}$ levels (Figure $4 \mathrm{C}$ ), when compared with the normal control group (Group I). However, the caffeic acid-administered animal groups (groups III and IV exhibited SOD, CAT and GSH levels comparable to those of normal rats.

\section{Effect of caffeic acid on serum lipid profile}

Results of serum lipid profile determination in different animal groups showed that the concentrations of TGls, TChl and low-density lipoprotein cholesterol (LDL-C) were increased, whereas the concentration of HDL-C was decreased markedly in the diabetic group (group II), relative to the normal control group (Table 2). Interestingly, oral treatment of caffeic acid at doses of $25 \mathrm{mg} / \mathrm{kg}$ body weight (group III) and $35 \mathrm{mg} / \mathrm{kg}$ body weight (group IV) resulted in marked decrease in the concentrations of TGls, TChl and LDL-C, and increases in HDL-C concentration.

\section{Histopathological features of pancreas}

Pancreatic sections from the normal animal group depicted normal-sized islets (Figure $5 \mathrm{~A}$ ). However, microscopic examination of pancreatic sections from the diabetic control group (group II) revealed that the diabetic rats had decreased number of $\beta$-cells, indicating evidence of $\beta$-cells destruction (Figure $5 \mathrm{~B}$ ). The islet structure was almost fully preserved in sections from groups III and IV (caffeic acid-treated groups), and there was hardly any pathological changes in their architecture (Figure $5 \mathrm{C}$ and D).

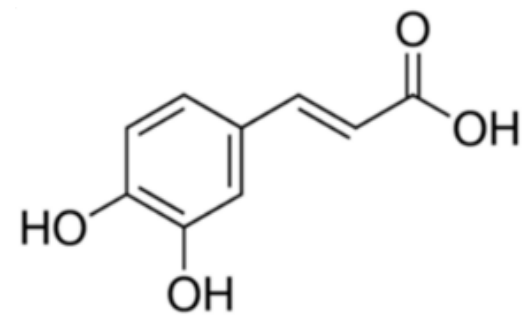

Figure 1: Molecular structure of caffeic acid.

Table 1: Effect of caffeic acid treatment on the body weight of diabetic rats

\begin{tabular}{lcc}
\hline Animal group & $\begin{array}{c}\text { Initial weight } \\
(\mathbf{g})\end{array}$ & $\begin{array}{c}\text { Final } \\
\text { weight } \mathbf{( g )}\end{array}$ \\
\hline Group I (Normal) & $172 \pm 0.87$ & $219 \pm 0.76^{\mathrm{a}}$ \\
Group II (Diabetic) & $174 \pm 0.85$ & $143 \pm 0.54^{\mathrm{b}}$ \\
Group III (Diabetic + & $169 \pm 0.92$ & $210 \pm 0.95^{\mathrm{a}}$ \\
25mg/kg caffeic acid) & & \\
Group IV (Diabetic + & $171 \pm 0.86$ & $220 \pm 1.3^{\mathrm{a}}$ \\
35mg/kg caffeic acid) & &
\end{tabular}

Values are mean \pm SD. Values with different superscripts differ significantly with each other $(p<$ 0.05 ) as assessed using Duncan's multiple range test 
Table 2: Effect of caffeic acid treatment on the lipid profile of diabetic rats

\begin{tabular}{|c|c|c|c|c|}
\hline \multicolumn{5}{|c|}{ Lipid profile } \\
\hline Group & Triglycerides & Total cholesterol & HDL Cholesterol & LDL Cholesterol \\
\hline Group I (Normal) & $71.87 \pm 1.21^{\mathrm{a}}$ & $91.42 \pm 1.56^{a}$ & $52.83 \pm 0.96^{a}$ & $22.66 \pm 0.69^{a}$ \\
\hline Group II (Diabetic) & $157.12 \pm 2.17^{b}$ & $158.43 \pm 1.86^{b}$ & $28.71 \pm 0.86^{b}$ & $97.22 \pm 1.33^{b}$ \\
\hline $\begin{array}{l}\text { Group III (Diabetic + } 25 \\
\mathrm{mg} / \mathrm{kg} \text { caffeic acid) }\end{array}$ & $74.08 \pm 1.16^{a}$ & $93.52 \pm 1.44^{a}$ & $49.93 \pm 1.09^{a}$ & $26.17 \pm 0.78^{a}$ \\
\hline $\begin{array}{l}\text { Group IV (Diabetic }+35 \\
\mathrm{mg} / \mathrm{kg} \text { caffeic acid) }\end{array}$ & $72.64 \pm 1.43^{a}$ & $92.03 \pm 1.51^{a}$ & $51.63 \pm 1.17^{a}$ & $23.94 \pm 0.79^{a}$ \\
\hline
\end{tabular}

Values are mean \pm SD values. Values with different superscripts in a particular column differ significantly with each other $(p<0.05)$, as assessed via Duncan's multiple range test.

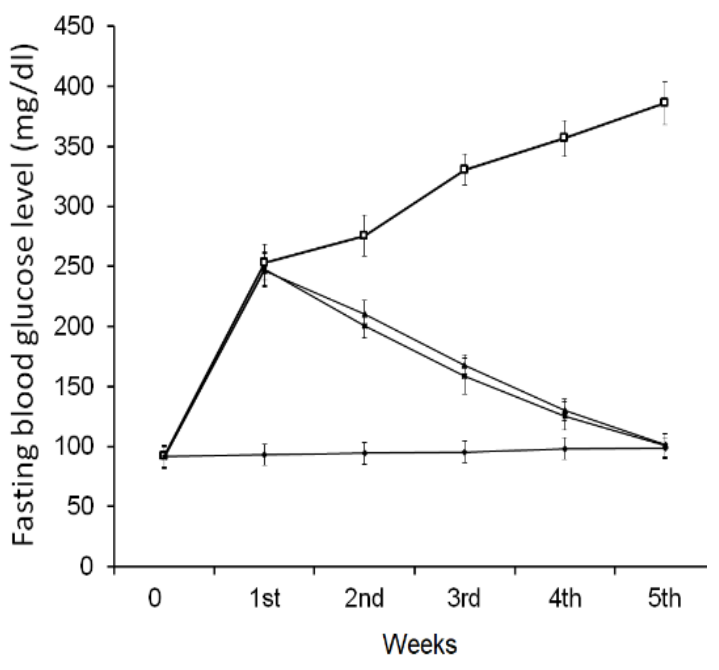

Figure 2: Effect of caffeic acid treatment on fasting blood glucose levels in different rat groups. The experiments were performed in triplicate. Key: normal rat group, $\square=$ diabetic rat group, $\boldsymbol{\Delta}=$ diabetic + $25 \mathrm{mg}$ caffeic acid group, and $\mathbf{m}=$ diabetic $+35 \mathrm{mg}$ caffeic acid group. Values are expressed as mean \pm $\operatorname{SD}(p<0.05)$

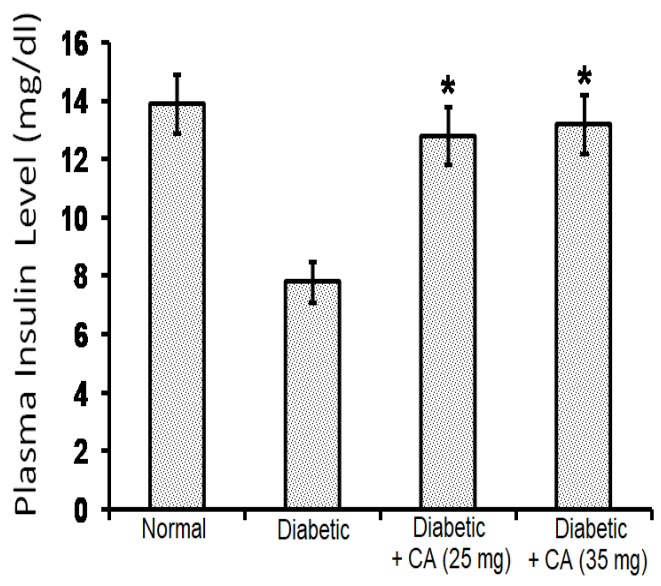

Figure 3: Effect of caffeic acid treatment on plasma insulin levels in different rat groups. The experiments were performed in triplicate. Values are expressed as mean \pm SD $(p<0.05)$
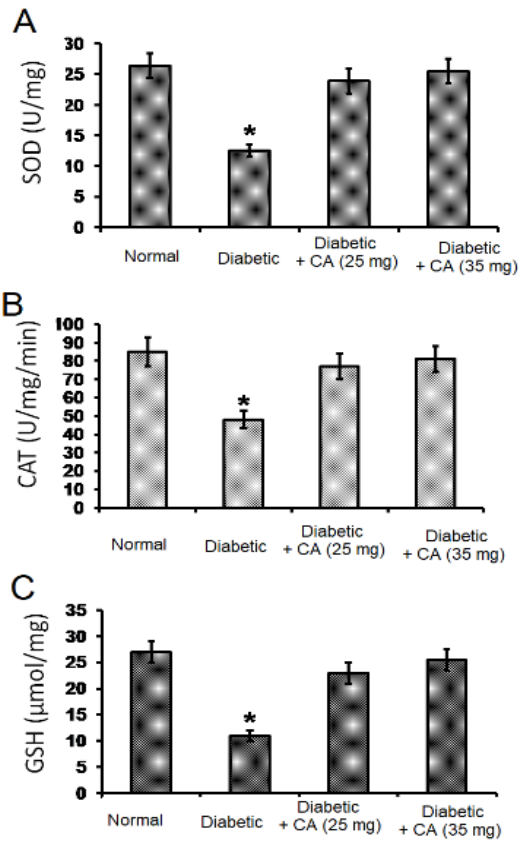

Figure 4: Antioxidant potential of caffeic acid. (A) SOD activity (B) CAT activity (C) GSH levels in different rat groups. The experiments were performed in triplicate, and values are expressed as mean \pm SD $\left({ }^{*} p<0.05\right)$
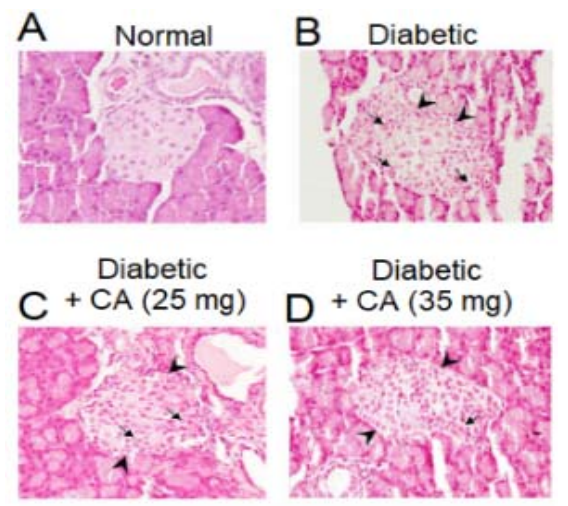

Figure 5: Effect of caffeic acid on the histopathological features of different rat groups ( $H$ \& $E$ staining). (A) Normal, (B) Diabetic, (C) Diabetic + caffeic acid (25 $\mathrm{mg} / \mathrm{kg}$ ) (D) Diabetic + caffeic acid (35 mg/kg). The experiments were performed in triplicate 


\section{DISCUSSION}

Recent studies have shown that high incidence of diabetes mellitus has imposed tremendous concerns on human health across the globe. The disease results in high level of lethality in the developed countries. Against this backdrop, researchers are actively involved in exploring possibilities of evolving various treatment strategies which can prove handy in the fight against diabetes. Studies conducted in recent years have shown the importance of animal models in understanding the molecular mechanism of diabetes mellitus. Diabetes is chemically induced in mice using chemical compounds, for example streptozotocin. In rats, streptozotocin induces high blood glucose levels, low plasma insulin and very low body weight, the weight loss being due to excessive protein breakdown as energy source [11]. In the current study, the diabetic rats consistently showed very high glucose levels, low body weight and low plasma insulin.

However, when the diabetic rats were treated with caffeic acid, there were significant decreases in fasting blood glucose levels, most likely due to the enhancement of insulin levels. The increase in insulin might have resulted from increased insulin secretion from pancreas and/or regeneration of pancreatic $\beta$-cells, as has been proposed in previous studies [12,13]. Similar anti-diabetic effects have been observed for caffeic acid esters in previous reports [14]. Due to decrease in insulin levels in the diabetic state, blood glucose is not used for energy production, and as such, excessive fatty acid levels accumulate in the liver due to their mobilization from the adipose tissue. These are converted to triglycerides in the liver, thereby manifesting as abnormal lipid profile [15].

The potency of anti-diabetic agents is also expressed in terms of their effect on the lipid profile of diabetic patients. In the present study, caffeic acid was found to decrease the blood glucose levels of the diabetic rats. It has been shown that there is excessive production of reactive oxygen species (ROS) in diabetes due to reduction in anti-oxidant potential, manifested in decreases in levels of enzymatic (SOD and CAT) and non-enzymatic (GSH) antioxidants [16]. Hence, in this study, caffeic acid has emerged as a potential anti-diabetic agent since its treatment led to significant enhancement in antioxidant potential of diabetic rats. Moreover, the anti-diabetic potential of caffeic acid was evident in its potential to exert protective effects on pancreatic islets of streptozotocin-induced diabetes rats.

\section{CONCLUSION}

The findings of this study reveal that caffeic acid enhances serum insulin levels, and decreases fasting blood glucose level of diabetic rats. Caffeic acid also exerts antioxidant effects by increasing the levels of GSH, CAT and SOD. These results suggest the potent antioxidant and anti-diabetic potential of caffeic acid in diabetic rat mode may the potentials of the compound for the clinical management of diabetes in humans.

\section{DECLARATIONS}

\section{Acknowledgement}

The authors of the manuscript are thankful to Heilongjiang University of Chinese Medicine, China for providing the facilities to conduct the presented work.

\section{Conflict of interest}

No conflict of interest is associated with this work.

\section{Contribution of authors}

We declare that this work was done by the authors named in this article and all liabilities pertaining to claims relating to the content of this article will be borne by the authors. Wenguang $\mathrm{Xu}$ and Xiuying Wen performed the study and contributes in the writing of manuscript. Ming Xiao, Qijian Mei contributes in the statistical analysis and collected the data. Qiong Luo was designed the protocol, supervise the study and writes the manuscript.

\section{Open Access}

This is an Open Access article that uses a funding model which does not charge readers or their institutions for access and distributed under the terms of the Creative Commons Attribution License (http://creativecommons.org/licenses/by/ 4.0) and the Budapest Open Access Initiative (http://www.budapestopenaccessinitiative.org/rea d), which permit unrestricted use, distribution, and reproduction in any medium, provided the original work is properly credited.

\section{REFERENCES}

1. Zheng $Y$, Ley SH, Hu FB. Global aetiology and epidemiology of type 2 diabetes mellitus and its complications. Nat Rev Endocrinol 2018; 4(2): 88-92. 
2. Simpson RW, Shaw JE, Zimmet PZ. The prevention of type 2 diabetes-lifestyle change or pharmacotherapy? A challenge for the 21st century. Diabet Res Clin Pract 2003; 59(3): 165-180.

3. Boutayeb $A$, Boutayeb $S$. The burden of noncommunicable diseases in developing countries. Int $\mathrm{J}$ Equity Health 2005; 4(1): 2-5.

4. Bell GI, Polonsky KS. Diabetes mellitus and genetically programmed defects in $\beta$-cell function. Nature 2001; 414(6865):788.

5. Aronoff SL, Berkowitz K, Shreiner B, Want L. Glucose metabolism and regulation: beyond insulin and glucagon. Diabetes spectrum. 2004; 17(3): 183-190.

6. O'Rahilly S, Barroso I, Wareham NJ. Genetic factors in type 2 diabetes: the end of the beginning? Science 2005; 307(5708): 370-373.

7. Li AN, Li S, Zhang YJ, XU XR, Chen YM, Li HB. Resources and biological activities of natural polyphenols. Nutrients 2014; 6(12): 6020-647.

8. Soto-Vaca A, Gutierrez A, Losso JN, XU Z, Finley JW. Evolution of phenolic compounds from color and flavor problems to health benefits. J Agri Food Chem 2012; 60(27): 6658-6677.

9. Ali Asgar MD. Anti-diabetic potential of phenolic compounds: A review. Int J Food Prop 2013; 16(1): 91 103.

10. Combs TP, Wagner JA, Berger J, Doebber T, Wang WJ, Zhang BB, Tanen M, Berg AH, O'Rahilly S, Savage DB,
Chatterjee K. Induction of adipocyte complement-related protein of 30 kilodaltons by PPARY agonists: a potential mechanism of insulin sensitization. Endocrinology 2002; 143(3): 998-1007.

11. Nyika A. Animal research ethics in Africa: an overview. Acta Tropica 2009; 112: S48-S52.

12. Newsholme $P$, Keane KN, Carlessi $R$, Cruzat V. Oxidative stress pathways in pancreatic $\beta$-cells and insulin-sensitive cells and tissues: importance to cell metabolism, function, and dysfunction. Am J Physiol Cell Physiol 2019; 317(3): C420-C433.

13. Myasnikova D, Osaki T, Onishi K, Kageyama T, Molino BZ, Fukuda J. Synergic effects of oxygen supply and antioxidants on pancreatic $\beta$-cell spheroids. Sci Rep. 2019; (1): 1802

14. Celik S, Erdogan S, Tuzcu M. Caffeic acid phenethyl ester (CAPE) exhibits significant potential as an antidiabetic and liver-protective agent in streptozotocininduced diabetic rats. Pharmacol Res2009; 60(4): 270276

15. Adlersberg $D$, Eisler L. Circulating lipids in diabetes mellitus. J Am MedAssoc1959; 170(11): 1261-1265.

16. Wagener FA, Dekker D, Berden JH, Scharstuhl A, Van der Vlag J. The role of reactive oxygen species in apoptosis of the diabetic kidney. Apoptosis 2009; 14(12): 1451-1458. 